\title{
NUEVA ARQUITECTURA TRADICIONAL A BAJO CONSUMO DE ENERGÍA EN LA AMAZONÍA PERUANA
}

\author{
NEW TRADITIONAL ARCHITECTURE WITH LOW \\ ENERGY CONSUMPTION IN THE PERUVIAN \\ AMAZON
}

\author{
PIERRE-MARIE GILLES \\ École Nationale Ponts et Chaussées \\ ALBERTO RÍOS \\ Universidad Nacional de Ingeniería
}

En la ciudad de Iquitos, en la Amazonía peruana, los materiales utilizados para las construcciones sólidas o permanentes (arena, cemento y ladrillos) son llamados nobles, lo que implica que los otros materiales no lo son, por ejemplo, la madera. Este material es considerado primordial en las construcciones tradicionales de las culturas locales y también por los ciudadanos menos favorecidos instalados en zonas urbanas. La madera también presenta muchas ventajas con respecto al impacto ambiental (huella de carbono), los costos de construcción en la Amazonía y la pasividad térmica (no acumula el calor). Deseamos así presentar una obra arquitectónica realizada en la ciudad de Iquitos en los años 2012-2013, concebida con madera de construcción e inspirada en los principios de ventilación de las construcciones tradicionales de culturas locales. Y que además ha sabido responder al paso del tiempo manteniendo su eficiencia en materia de comportamiento energético.

clima ecuatorial, madera, aire acondicionado natural (ventilación), construcciones tradicionales, arquitectura sostenible
NÉSTOR NEVADO

Escuela Nacional de Arquitectura de Versalles

SYLVAIN GILLES

Universidad de Montpellier

Recibido: 5 de julio del 2020

Aprobado: 28 de agosto del 2020

doi: https://doi.org/10.26439/limaq2021.n008.5554

In the city of Iquitos, in the heart of the Peruvian Amazon, the materials used for solid or permanent constructions (sand, cement, bricks) are called noble, implying that other materials, such as wood, for example, are not. Wood, however, is of primary importance in the traditional constructions of local cultures and for most humble citizens living in urban areas. This natural material presents many advantages, such as a lower ecological impact (carbon footprint), a lower construction costs and better thermal insulation (not passive because it does not accumulate heat). We want to present an architectural work carried out in Iquitos in 2012-2013, with local construction wood and inspired by the ventilation principles of traditional local constructions, which has responded to the passage of time while maintaining its efficiency in terms of energy performance.

equatorial climate, wood, natural air conditioner (ventilation), traditional constructions, sustainable architecture 


\section{INTRODUCCIÓN}

Este artículo presenta una construcción única en la ciudad de Iquitos, que se ubica en la zona del clima ecuatorial de la Amazonía peruana, a una altitud de $106 \mathrm{~m}$.

Este clima se caracteriza por parámetros ambientales muy constantes tanto por las estaciones como por la duración de los días y las noches. La presencia de la selva y de los ríos mantiene la humedad en un nivel alto y otorga una frescura diurna y nocturna en el campo. Durante el transcurso del año, la temperatura generalmente varía de $22^{\circ} \mathrm{C}$ a $32{ }^{\circ} \mathrm{C}$ y rara vez baja a menos de $20{ }^{\circ} \mathrm{C}$ o sube a más de $34{ }^{\circ} \mathrm{C}$. Con la ausencia de la fuerza de Coriolis que provoca ciclones y una capa de nubes casi constante que refleja las radiaciones solares, que van en aumento a causa del calentamiento global, el clima ecuatorial asegura una estabilidad en comparación a los demás. Esto es muy importante para que una vivienda se abra a su entorno, como la que presentamos en esta publicación.

El nivel de humedad en el aire está también en aumento. En la actualidad, las ciudades con este clima afrontan el calor y la humedad ambiental con sistemas de aire acondicionado. Esta situación se debe, por un lado, al uso generalizado del concreto, que es un material que acumula el calor. Y, por otro, es provocada también por el hecho de seguir principios de una arquitectura de tipo occidental, con pocas aberturas, signo de un individualismo generalizado.

Con una energía barata esta situación es factible, pero, como ya hemos sobrepasado el pico de producción mundial de petróleo, su precio irá aumentando inexorablemente. Es por eso que una arquitectura sostenible deberá prevalecer en el futuro, con el uso de la madera, ampliamente disponible en la Amazonía y un diseño que favorezca la ventilación.

\section{ANTECEDENTES}

En las áreas rurales de la Amazonía, tradicionalmente las casas (malocas) se encuentran relativamente espaciadas entre ellas, están hechas con madera y sobre zancos elevados a un metro del suelo, y únicamente limitadas con una baranda perimétrica. Eventualmente están cerradas por uno de sus ángulos donde se ubican los espacios húmedos, como duchas o baños. El techo está cubierto con hojas de palmera (irapay, Lepidocaryum gracile); es muy inclinado, con un desbordamiento de alrededor de $1,5 \mathrm{~m}$ y con una baja altura (véase la figura 1), sin cielo raso. Se hace uso de hamacas para dormir y la cocina consiste en una mesa de madera revestida con tablas y rellenada de barro. 


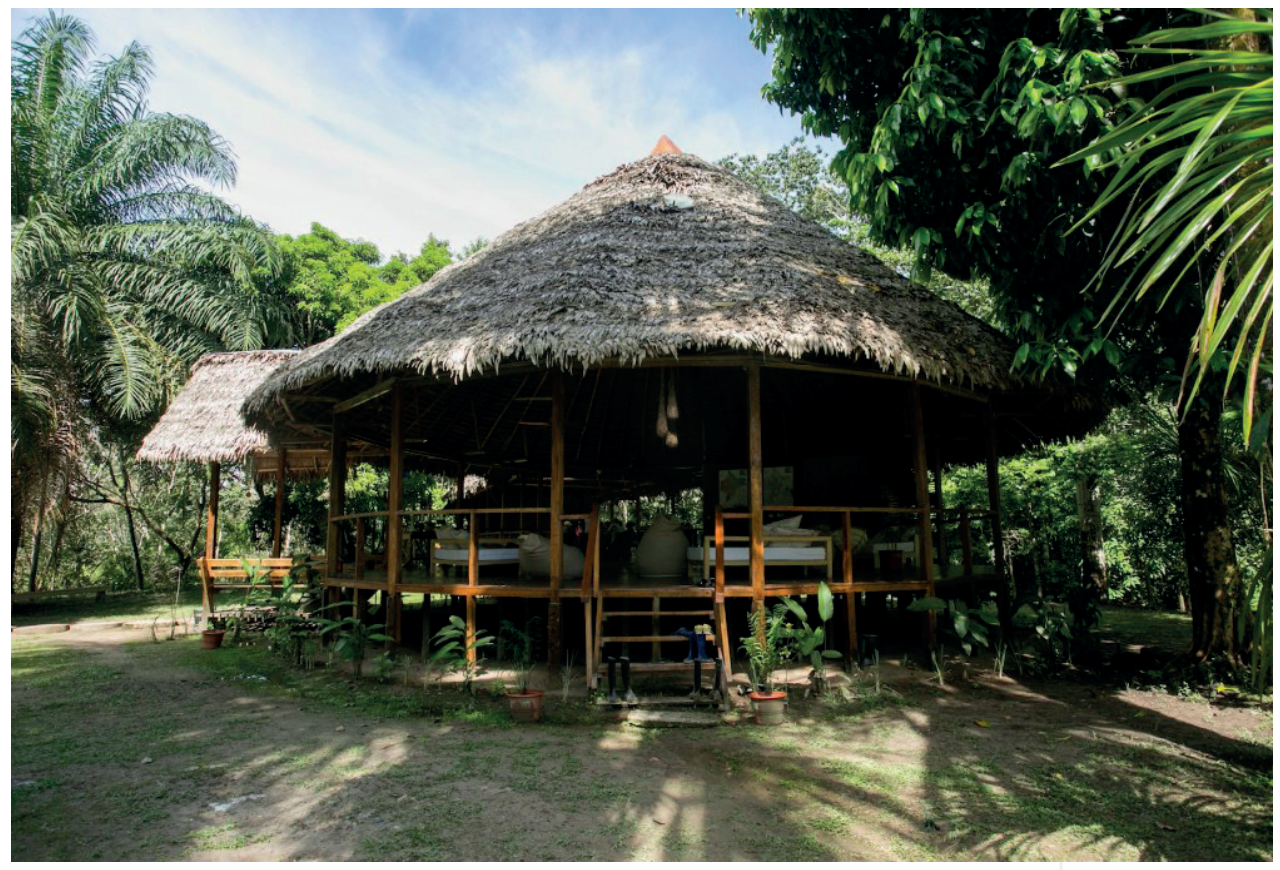

Las ganas de vivir y trabajar llevaron a la creación de una vivienda-taller dedicada a una empresa productora de aceites esenciales. Una pareja francesa inició este proyecto y Sylvain Gilles, hidrobiólogo investigador de un centro de investigación del Estado, hizo la obra. La puesta en marcha del proyecto pasó primero por la ubicación del terreno, su accesibilidad, un lugar alto para aprovechar la vista y la ventilación, y un contexto urbano-social con las mismas motivaciones.

El terreno se ubica en un asentamiento humano cerca de la ruta que une Iquitos y Nauta. Dos condiciones fueron importantes para la elección del terreno: la primera fue la de escapar a la contaminación sonora y atmosférica de la ciudad, acercándose a la selva. Y la segunda fue la seguridad: al encontrarse en un entorno urbano nuevo, los lazos con los vecinos aportarían confianza y seguridad.

La concepción de la casa estuvo influenciada por la arquitectura tradicional caribeña y la arquitectura local (maloca).

Figura 1.

La maloca amazónica

Fotografía:

Guillain Estivals 
Figura 2

Ubicación del

proyecto en el número 28

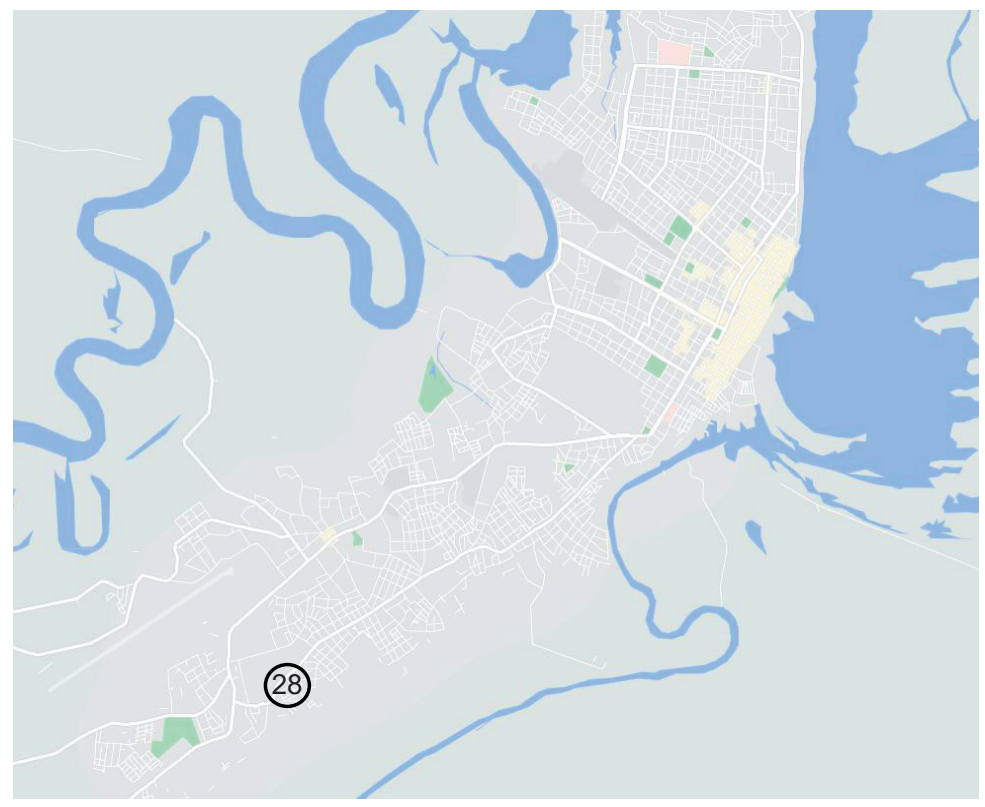

\section{REALIZACIÓN DEL PROYECTO}

Se compraron primero cuatro lotes contiguos en el asentamiento humano (véase la figura 2), los números 9, 10, 44 y 43 . El lote 9 medía $8 \mathrm{~m} \times 15 \mathrm{~m}$, los demás $6 \mathrm{~m} \times 15 \mathrm{~m}$. Se encuentran entre dos pasajes, La Participación y 26 de Febrero. El taller fue construido en el fondo de los lotes 43 y 44 con dimensiones de $4 \mathrm{~m} \times 12 \mathrm{~m}$, y con acceso al segundo pasaje. La casa fue construida en el medio de los cuatro lotes. Cuatro muros perimétricos provisionales, hechos con ladrillos y cemento, protegieron la obra y fueron destruidos cuando se compraron los lotes 11, 42 y 45 para aprovechar una huerta y construir una casita de guardia en el fondo del lote 42 .

El diseño y la ejecución fueron encargados a dos arquitectos: Pierre-Marie Gilles (Francia) y Alberto Ríos (Perú). La construcción del taller fue realizada con ladrillos y concreto; la casa fue hecha enteramente en madera. Los elementos de principio de la casa fueron el no uso de muros periféricos, como una maloca, con el fin de favorecer ventilación y resistencia a los vientos y tormentas. Así, la casa se convierte en un solo gran balcón con una vista de $225^{\circ}$ y con cerramientos hechos de ventanas-persianas movibles. Las columnas son puestas en pantalla según una trama de $3,5 \mathrm{~m}$, la escalera en caracol se ubica en el centro de la fachada principal. En el primer piso, que tiene una función evidentemente más social, se realizaron espacios cerrados complementarios al taller y un espacio de hamacas. El piso de arriba tiene una función más íntima, pero también independiente; cuenta con una habitación, cocina y baños. 


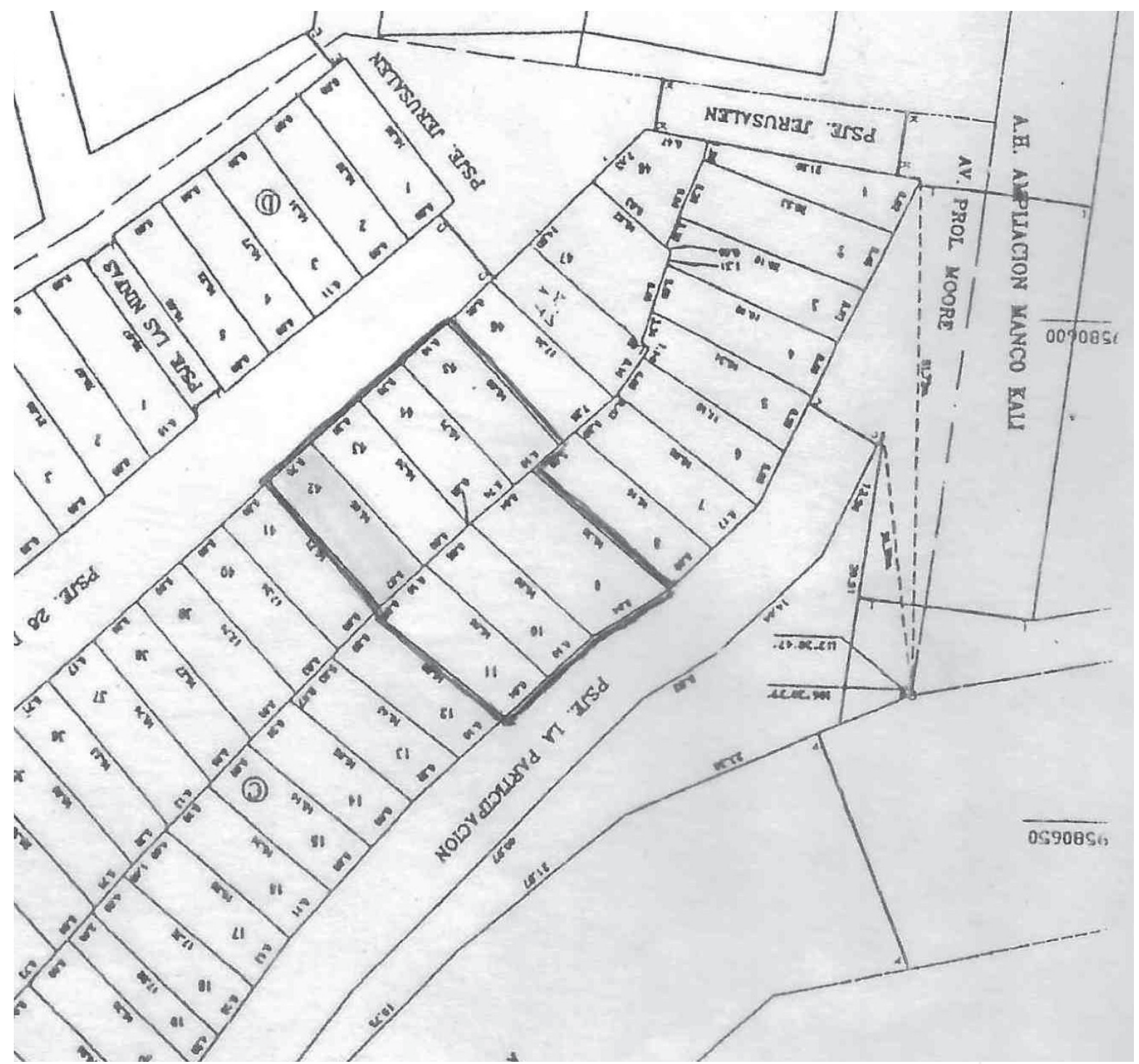

Figura 3.

Ubicación de

los lotes en el

asentamiento

humano

Fuente:

Secretaría General

Asentamiento

Humano 26 de

Febrero, lquitos 
Figura 4

Primer piso, terraza

Fotografía:

Guillain Estivals

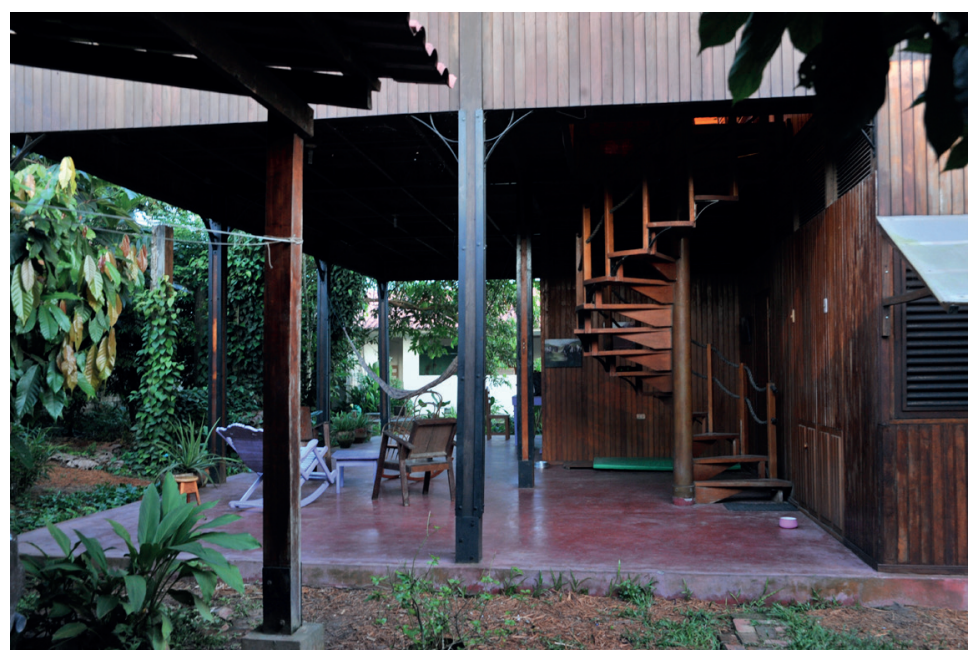

Figura 5 .

Cimentación

del primer piso

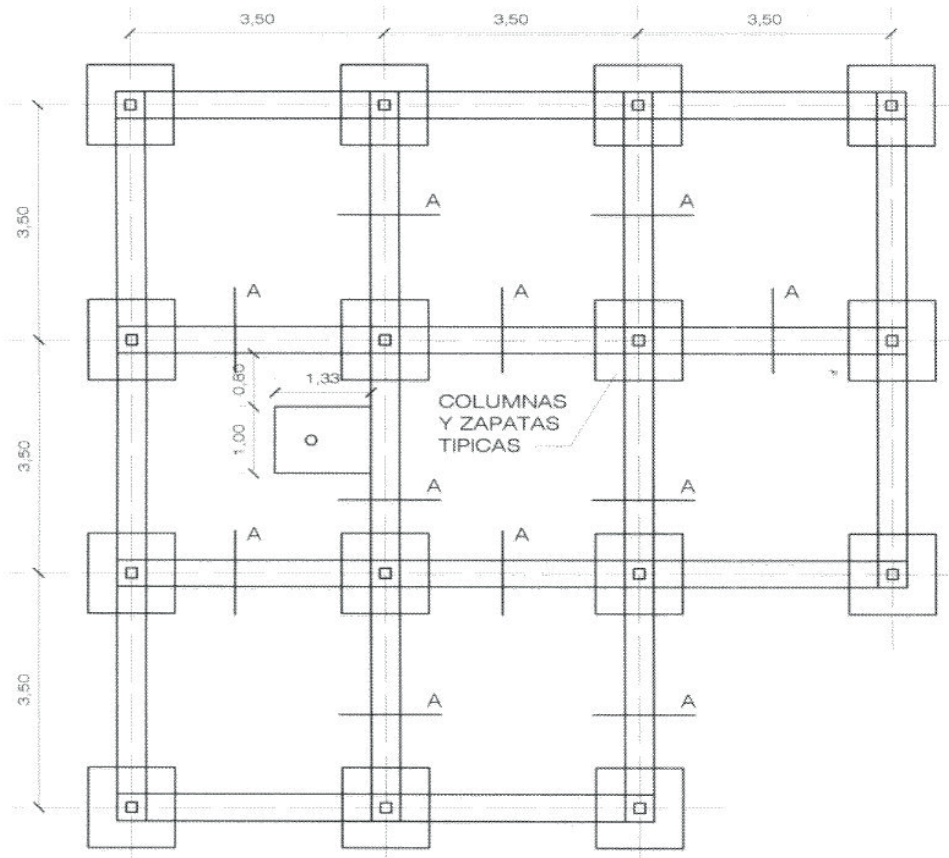

Elaboración propia 


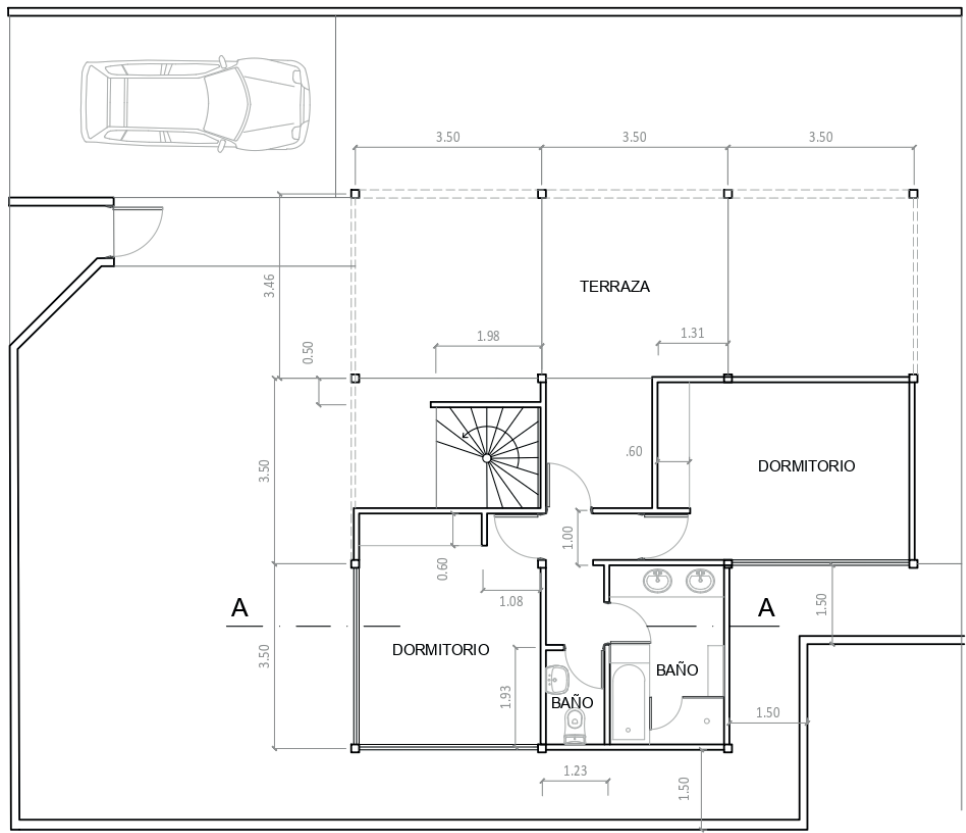

Figura 6 .

Primer piso

Elaboración propia

La casa, vista desde arriba, tiene la forma de una punta de flecha, lo que permite en el segundo piso tener una vista de $225^{\circ}$, con una pared que aísla el dormitorio y los baños. En la zona de la sala-comedor se rompe la continuidad vertical de la columna del primer piso con el fin de tener un espacio lo más libre posible; así el techo es sostenido por un cinturón de vigas (véase la figura 7).

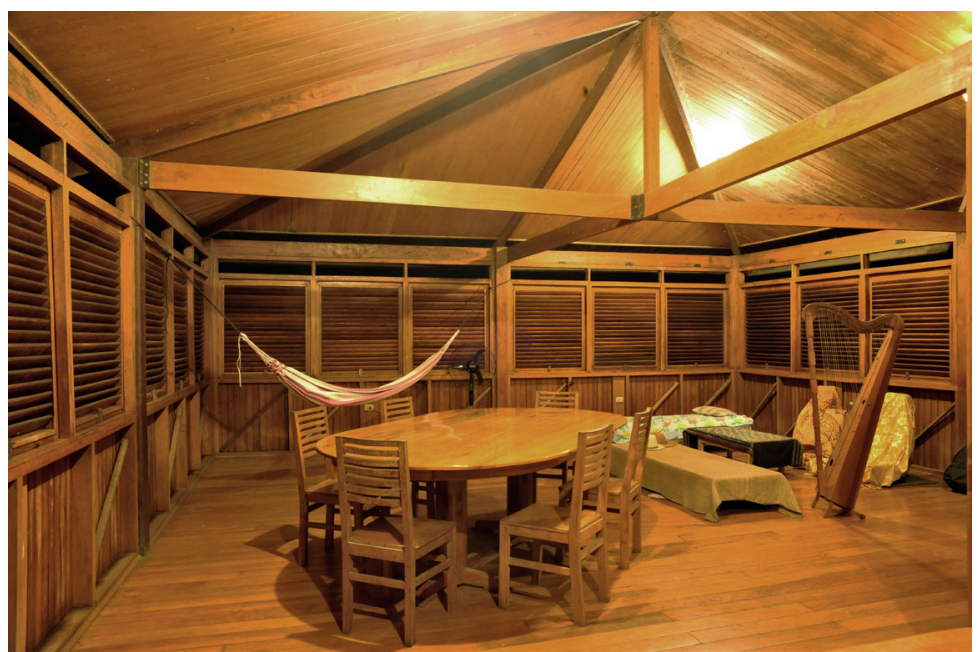

Figura 7.

Segundo piso, comedor

Fotografía:

Guillain Estivals 
Figura 8.

Segundo piso

Elaboración propia

Figura 9

Posición de las

ventanas en

ventilación

Fotografía: Guillain Estivals
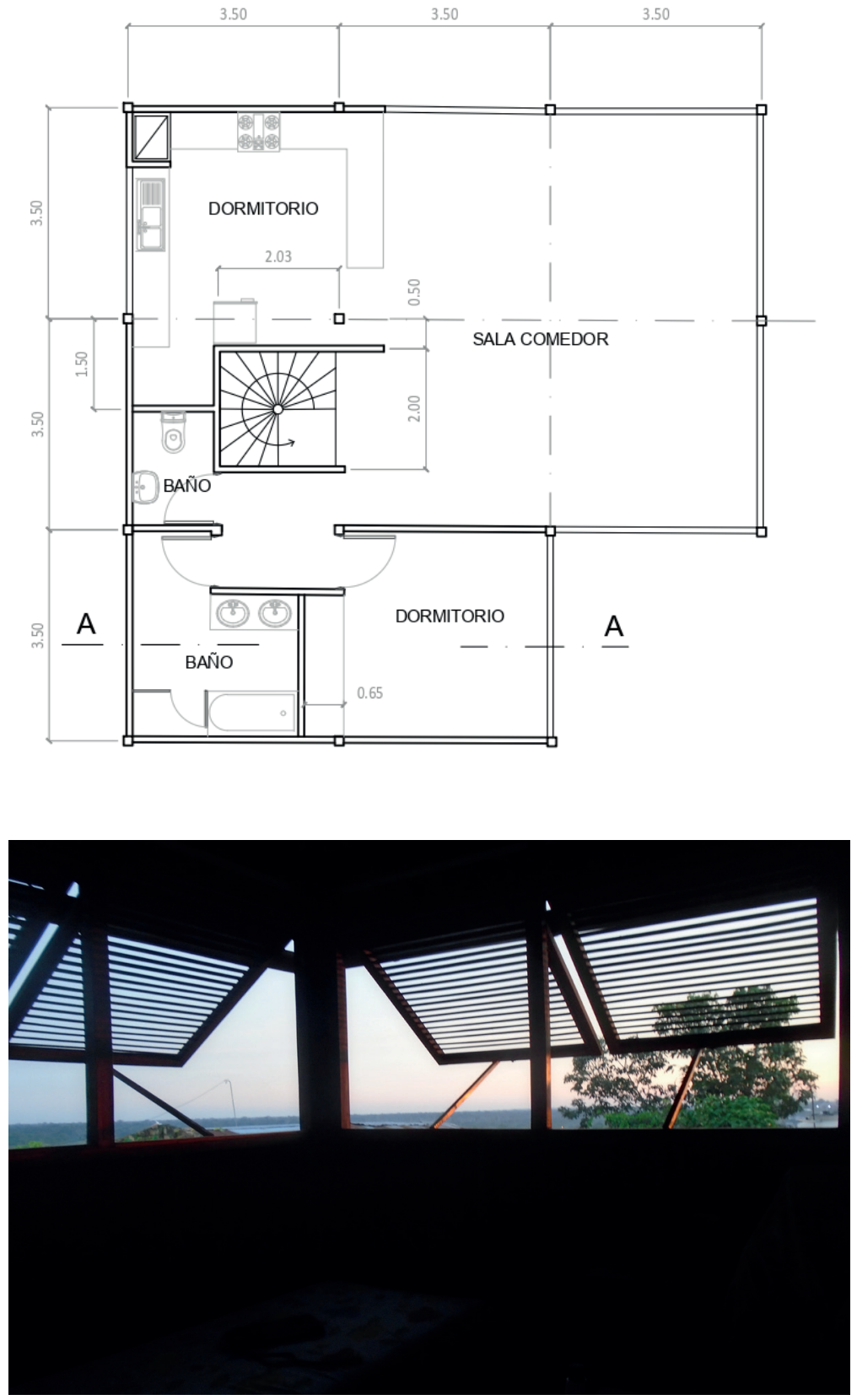
Las ventanas son mantenidas en posición de ventilación con palos de cedro de un metro de largo que colocan las persianas horizontales, lo que permite el paso del aire y de la luz. Esta posición única permite la visión del paisaje tras las tablitas de las persianas.

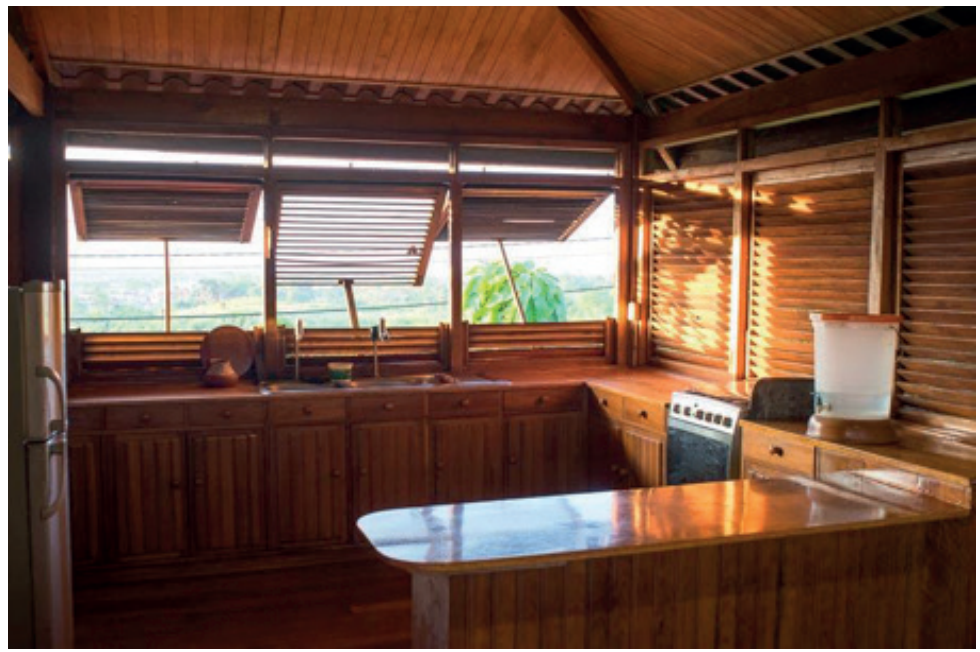

Figura 10.

Piso de arriba,

cocina

Fotografía:

Guillain Estivals

El techo está cubierto con tejas de plástico, lo que permite tener un peso mínimo. El aislamiento interior (véase la figura 4) está hecho con poliestireno expandido cubierto con tablas.

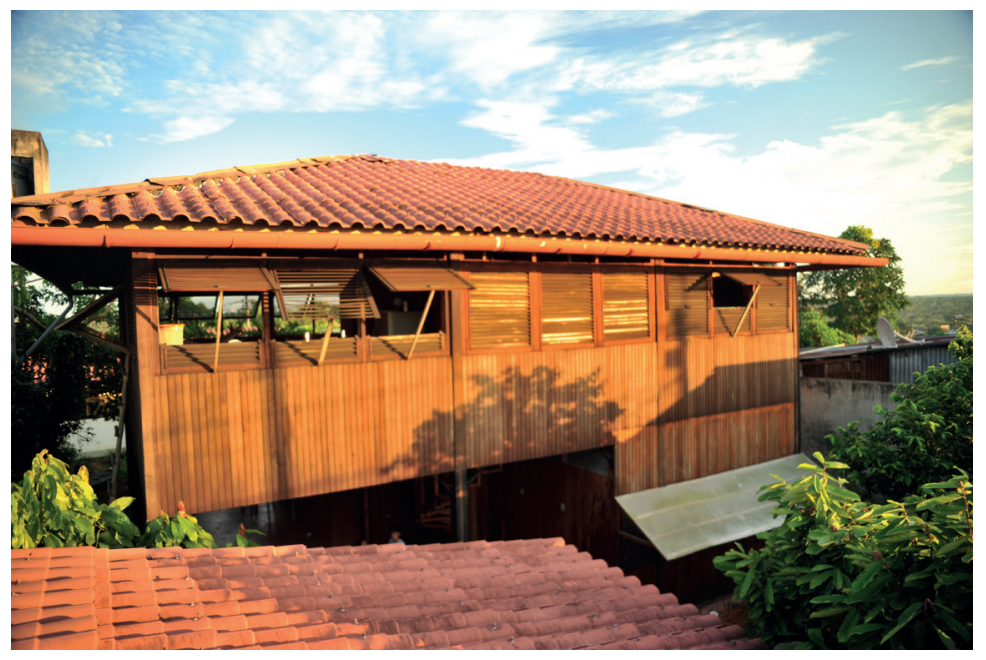

Figura 11 .

Techo y segundo piso, fachada noroeste; en primer plano, el techo del garaje

Fotografía:

Guillain Estivals 
Figura 12.

Fachada sureste,

segundo piso

Fotografía:

Guillain Estivals

Figura 13.

Estructura del techo

Elaboración propia

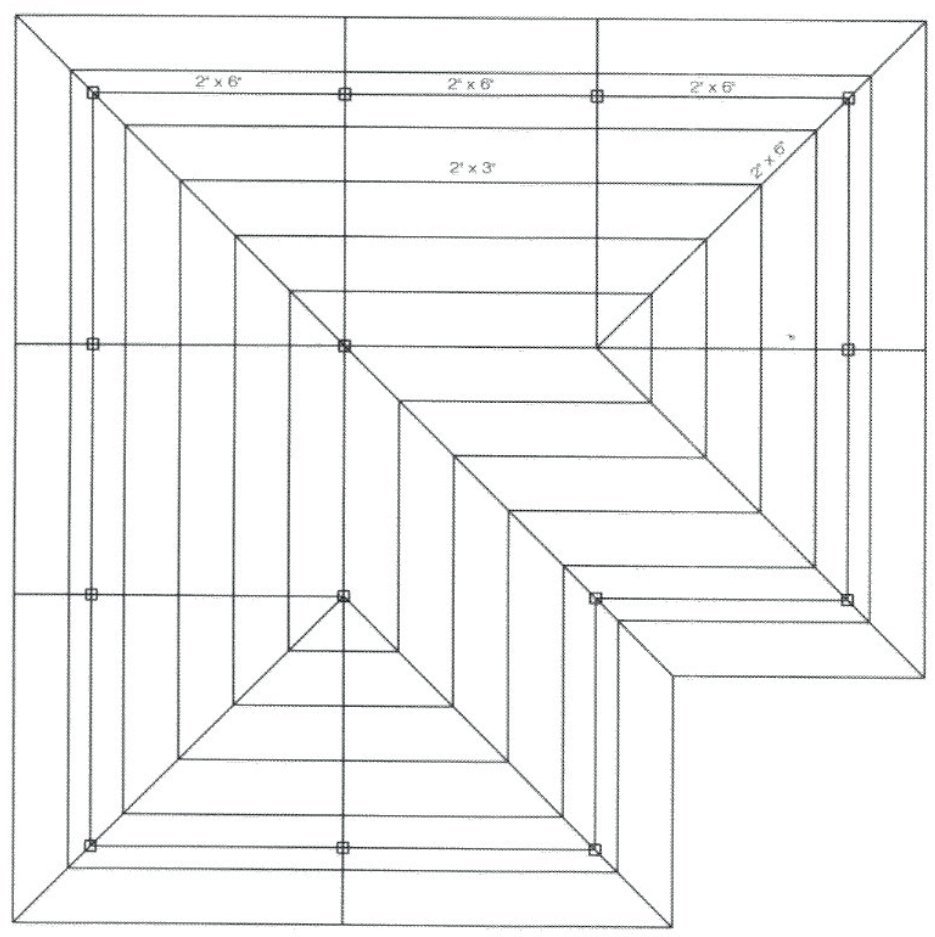




\begin{tabular}{ll}
\hline \multicolumn{1}{c}{ Calidad y nombre científico } & \multicolumn{1}{c}{ Volumen y uso } \\
\hline Capirona (Calycophyllum spruceanum) & $66 \mathrm{~m}^{3}$ en vigas, estructuras, paredes, piso \\
Tornillo (Cedrelinga cateniformis) & $6 \mathrm{~m}^{3}$ en muebles \\
Quinilla colorada (Manilkara bidentata) & $7 \mathrm{~m}^{3}$ en columnas principales \\
Mohena amarilla (Aniba amazonica) & $4,7 \mathrm{~m}^{3}$ en puertas y ventanas \\
Marupa (Simarouba amara) & $3,5 \mathrm{~m} 3$ en cielo raso \\
Cedro (Cedrela odorata) & Columna de la escalera en caracol \\
\hline
\end{tabular}

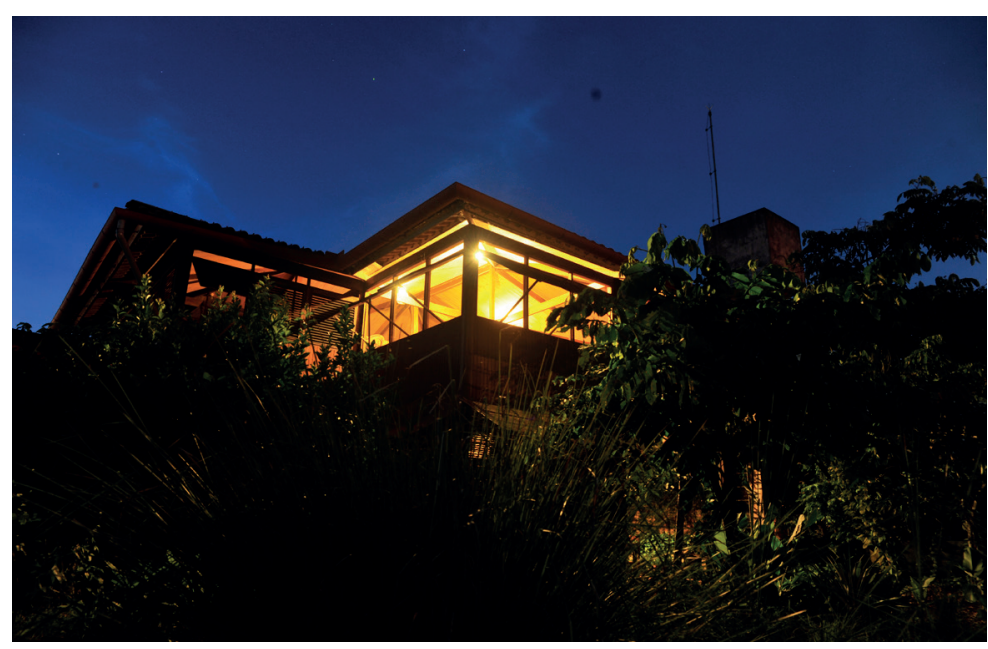

\section{DESCRIPCIÓN DE LA OBRA}

El taller fue construido antes de todo lo demás, para almacenar la madera y abrigar la obra de carpintería. El volumen total de madera utilizada fue de $87,3 \mathrm{~m}^{3}$.

Ocho carpinteros y seis albañiles trabajaron en la edificación de la casa durante tres meses. Se empezó con el segundo piso, donde los propietarios pudieron vivir mientras se terminaba el primer piso. El costo únicamente del taller y de la casa fue de 92000 dólares. Se encontró la capa freática a nueve metros de profundidad, caso excepcional considerando que el terreno está sobre una loma. Esto permite tener agua durante todo el año con una autonomía total. Un primer tanque enterrado de $2 \mathrm{~m}^{3}$ alimenta un tanque elevado de $0,6 \mathrm{~m}^{3}$, que permite tener agua con presión en las casas y enfriar el alambique en el taller. El costo mensual global del consumo de electricidad, que incluye las bombas para el agua, dos neveras, un congelador, una lavadora, equipos electrónicos y la luz, es en promedio de 40 dólares.

\section{Tabla 1}

Calidad de madera, volúmenes utilizados en la elaboración

\section{Elaboración propia}

Figura 14.

Fachada sureste

Fotografía:

Guillain Estivals 
Figura 15

Establecimiento de

las columnas, taller

en el fondo

Fotografía:

Guillain Estivals

Cuatro años después de la obra principal, las columnas del primer piso fueron reforzadas con fierros en los ángulos, y unas cuadraturas fueron colocadas entre ellas y las vigas del segundo piso.

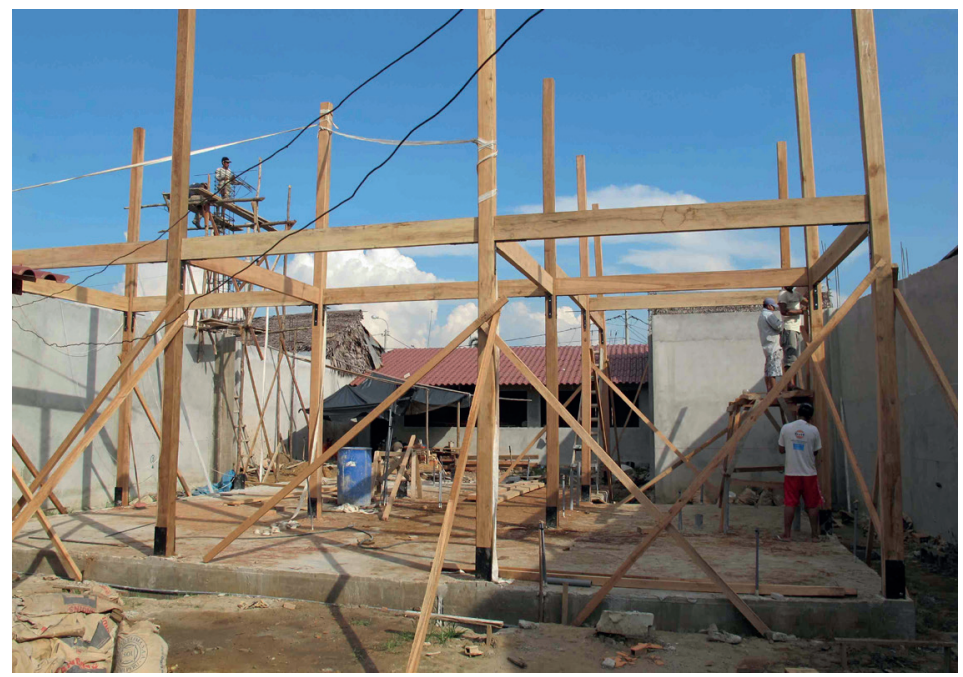

Figura 16

Establecimiento del

techo y del tanque

elevado

Fotografía:

Guillain Estivals

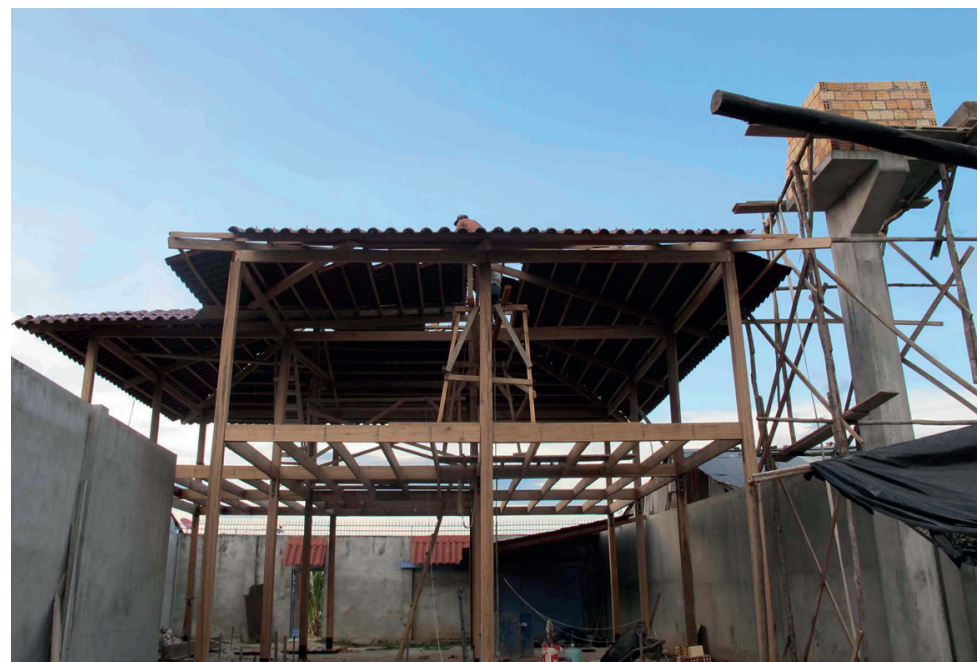




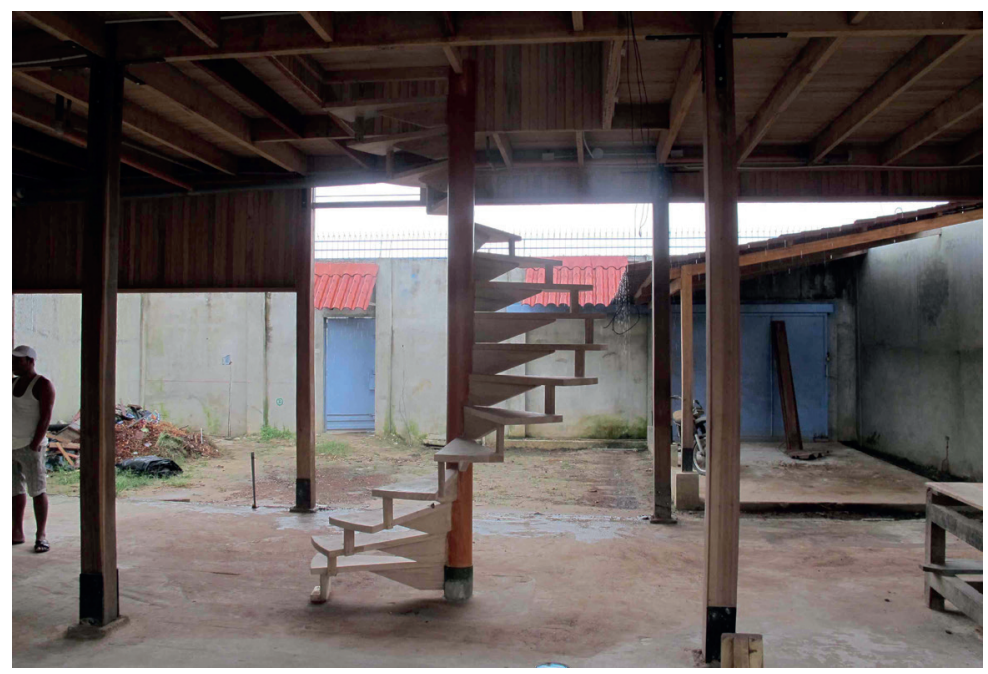

Figura 17.

Establecimiento de la escalera en caracol

Fotografía: Guillain Estivals

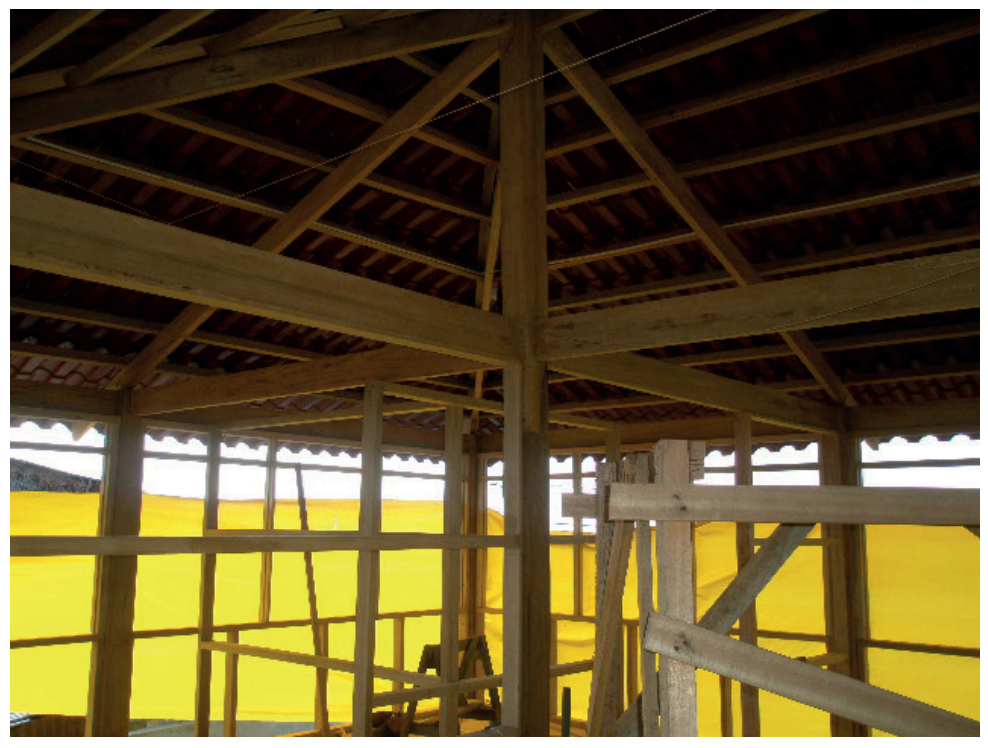

Figura 18.

Establecimiento del segundo piso

\section{Fotografía:}

Guillain Estivals

Unas canaletas fueron colocadas alrededor del techo; el agua de la lluvia es drenada con tuberías enterradas que se conectan a las alcantarillas de la calle.

Algunos elementos de la estructura secundaria de mala calidad, como las tablas de las paredes, fueron atacados por insectos xilófagos. Por otro lado, gracias a la constante ventilación no hubo propagación de hongos, muy presentes en este tipo de clima ecuatorial. La mayor parte del tiempo no se usan ventiladores, salvo en los días extremadamente calurosos. 
Durante el movimiento telúrico del año 2019, la estructura de la casa supo amortiguar la onda sísmica sin daños secundarios.

\section{ASPECTOS CULTURALES, SOCIALES Y ECONÓMICOS}

Durante siete años, el barrio insistió en la obtención de títulos de propiedad, puesto que los vecinos solo contaban con constancias de posesión de terrenos.

Nosotros, como miembros de la comunidad, participamos en las reuniones comunales logrando un intercambio cercano con los vecinos. La falta de aprovisionamiento de agua potable en el barrio y el hecho de tener un pozo de agua independiente creó lazos de solidaridad y confianza que borraron las diferencias culturales o los prejuicios existentes.

El comercio local permite proveernos de productos básicos, lo cual nos hace partícipes también en la vida del barrio con los vecinos. 